\title{
Factors Affecting Dietary Preferences for Genotypes of a Hybrid Wheatgrass
}

\author{
DOREEN R. TRUSCOTT AND PAT O. CURRIE
}

\begin{abstract}
Interspecific hybridization of grasses represents a valuable plant breeding procedure for developing new species with superior grazing value for livestock. Evaluations were made of the hybrid cross between quackgrass (Elytrigia repens [L.] Beauv.) $\times$ bluebunch wheatgrass (Pseudoroegneria spicata [Pursh.] Scribn and Smith) to determine how animal preferences for these hybrids were influenced by grazing season and year. Significant differences in the preference shown by steers as measured by bite counts in 1981 and percent utilization $(P<0.01)$ in 1982 existed among the 46 clonal lines for each of the 2 successive years. Preference rankings for lines selected the first year were not identical to those selected a second year although lines with high preference rankings the first year were generally preferred the second year. A clonal line, designated line 30, was most preferred in 7 of 8 subtrials in 1981 and ranked in the top 3 preferred plants in all trials in 1982. There was a 4-week period in early summer when preference differences were minimal. It was attributed to the abundant regrowth on all lines at this time and was found to have a significant $(P<0.01)$ effect on steers' dietary choices.
\end{abstract}

Key Words: bluebunch wheatgrass, quackgrass, forage, beef cattle

Interspecific hybridization of grasses represents a valuable plant breeding procedure to develop new species with superior grazing value for livestock. Particular success has been achieved by cross-

Authors are research associate, MAES, and range scientist, USDA-ARS, at the Fort Keogh Livestock and Range Research Station, Route 1, Box 2021, Miles City, Mont. 59301 .

This research is a contribution from the USDA, Agricultural Research Service (USDA-ARS), Fort Keogh Livestock and Range Research Station and the Montana Agricultural Experiment Station (MAES). Contribution No. J-1841 from Montana Agr. Exp. Sta.

The research reported was also in partial fulfillment of a graduate degree by D.R. Truscott at Colorado State University, Fort Collins. The authors wish to gratefully acknowledge Drs. W.A. Laycock, K.H. Asay, G.V. Richardson, and B.W. Knapp. USDA-ARS, and Drs. C.D. Bonham, N.A. Daugherty, and E.T. Bartlett, CSU for their support and contributions.

Manuscript accepted 14 July 1987.

JOURNAL OF RANGE MANAGEMENT 40(6), November 1987 ing bluebunch wheatgrass (Pseudoroegneria spicata [Pursh] Scribn and Smith) and quackgrass (Elytrigia repens [L.] Beauv.) $)^{1}$ which was designated RS-1 and RS-2 (Asay and Dewey 1981). An obstacle to the release of this RS hybrid for commercial use, however, has been the screening of lines within the hybrid to determine their value to livestock as range forages. Preferences exhibited by livestock for these genotypes are of particular interest as they affect the extent to which the plants will be utilized.

Preliminary studies using bite count data were conducted by Currie et al. (1981) on a group of RS hybrid lines to evaluate relative preferences by beef cattle. It was concluded that cattle preferentially selected between and within certain hybrid lines. There did not appear to be a distinct relationship between animal preference and the selection criteria established by plant breeders. Results suggested that characteristics which plant breeders have traditionally used to select new plants may not be reliable indicators of animal preferences. Similar conclusions were made from trials conducted a second year by the same scientists.

Asay et al. (1968) found that relative dietary preference ratings by rabbits and sheep for some lines of reed canarygrass (Phalaris arundinacea [L.]) were consistently high and others consistently low. Genetically, it was found that factors which controlled relative palatabilities were transmitted to successive plant progeny. Barnes et al. (1970) reported a fairly high heritability for palatability in studies with reed canarygrass. Consistent differences in apparent palatability have also been reported among genotypes of other species (Peterson et al. 1958). Thus, the reality of breeding heritable characteristics into plants to develop grass cultivars which are more preferable to the grazing animal appears to be an attainable goal. However, evaluation of plant materials would be enhanced by a more thorough understanding of the diet selection process.

INomemclature follows that proposed by Dr. D.R. Dewey (1984), Crops Research Laboratory, Logan, Utah. Previous nomenclature was Agropyron spicatum for bluebunch wheatgrass and Agropyron repens for quackgrass. 
This knowledge, in turn, could reduce the need to conduct grazing trials to evaluate the large plant populations necessary or often included in breeding programs. Our objectives were to establish preference rankings for $\mathbf{4 6}$ clones of the RS hybrid and to determine how observed rankings were affected by season of grazing and year-to-year variations.

\section{Materials and Methods}

A vigorous, productive cross between quackgrass and bluebunch wheatgrass designated as the RS hybrid was developed and stabilized by plant breeders at Logan, Utah (Asay and Dewey 1981). This RS hybrid is a morphological intermediate of the 2 parent species and displays a wide range of variability for many characteristics. Forty-six clones of the RS hybrid were planted on a semiarid, clay-loam range site at the Fort Keogh Livetock and Range Research Station, Miles City, Mont. Soils on this nearly level floodplain are classified as a Patent silty loam (fine-loamy, mixed calcareous, frigid Ustic Torriorthents (North Dakota 0103)). Drainage is good, and the $\mathrm{pH}$ is neutral to slightly basic.

Single plant plots of the $\mathbf{4 6}$ clonal hybrid lines were arranged within each replication on 1.0 -m centers in 2 rows of 23 plants each. Design for the study was a randomized complete block with 10 replications. Two rows of hybrid plants were planted around the periphery of the plot to minimize border effects. Individually cloned plants within the plot were identified by a marker placed flush with the soil surface.

\section{Grazing Trials}

Eight yearling Hereford steers with an average initial weight of $200 \mathrm{~kg}$ were gentled and used to evaluate grazing behavior and determine relative preferences for the 46 cloned RS hybrid plants. Replications 1 to 5 were fenced separately from replications 6 to 10 and are hereafter referred to as pastures 1 and 2, respectively. Four trials were conducted in each pasture. The first trial began $15 \mathrm{May}$ in pasture 1 and 1 June in pasture 2. Trials continued at 2-week intervals in alternate pastures through 28 August. Two days prior to a trial, steers were put in dry lot and were fed crested wheatgrass

TRIAL 1

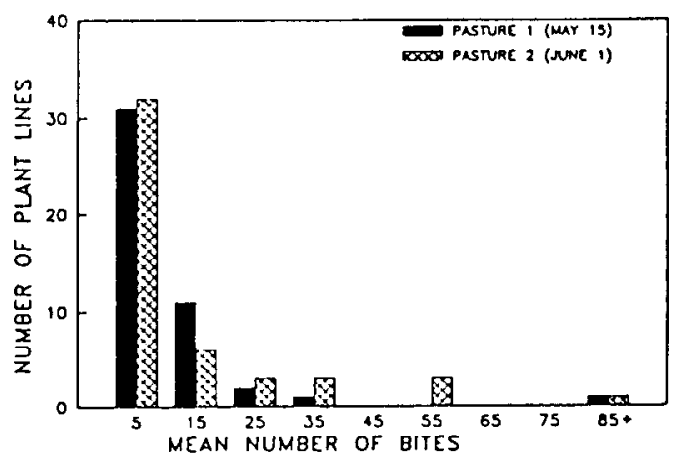

TRIAL 3

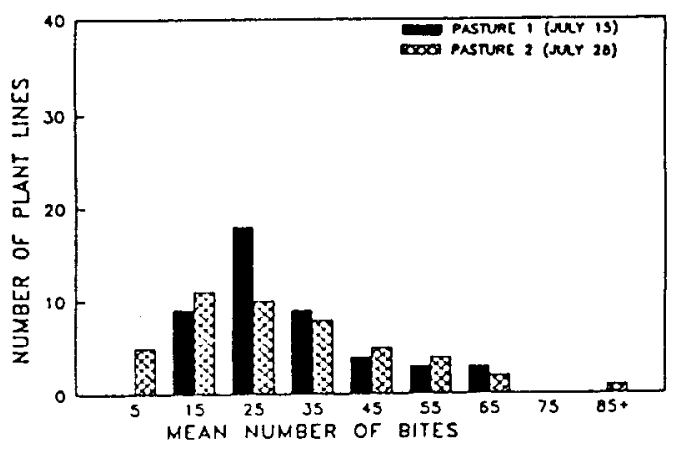

hay. Hay was fed at $1 \%$ of body weight until 1 hour prior to grazing. The purpose of drylotting the steers was to assure tameness and provide brief refresher training to facilitate their use. Steers were grazed on a crested wheatgrass-native forage pasture between each trial or they were used in a concurrent study of the hybrids at a different site. Sampling periods were started on the hour from 0600 to 0900 hours. Steers grazed the pasture in pairs for 30-min time periods during these hours. An observer recorded the plants grazed and number of bites taken per plant for each steer for each 30 -min time period. Steer pairings, times, and site of release were randomized for each trial.

Upon completion of a trial, all plants on each pasture site were clipped to a $10-\mathrm{cm}$ stubble height to keep subsequent trials from being affected by regrowth differences. Pastures were sprinkler irrigated between trials to ensure adequate and uniform regrowth. All feces and debris were removed from the plot immediately after a trial.

\section{Grazing Trials}

The same steers used in the 1981 trials were used again in 1982. The 1982 trials were conducted to establish relative preference rankings for the hybrids with groups of 4 steers grazing as a "herd". Pastures 1 and 2 were evaluated separately, but the steers were allowed to graze both pastures simultaneously. Again, 4 trials were conducted on each pasture at 4-week intervals from 15 May to 18 August. Steer groupings were randomized over all trials. Grazing was for 30-min time periods, after which animals were restrained while utilization measurements were made on the individual hybrid clones. After plant measurements were completed, steers were again released and allowed to continue grazing. This procedure was repeated until an overall utilization was reached which left an average stubble height of $10 \mathrm{~cm}$ for most of the clones within the entire plot. Relative preferences were measured by use of an "ocular-estimate" of percentage plant removal as described by Pechanec and Pickford (1937). These estimates were made after each 30 -min period and at the termination of the trial. Following a trial all remaining plant material was clipped to $10 \mathrm{~cm}$ height,

TRIAL 2

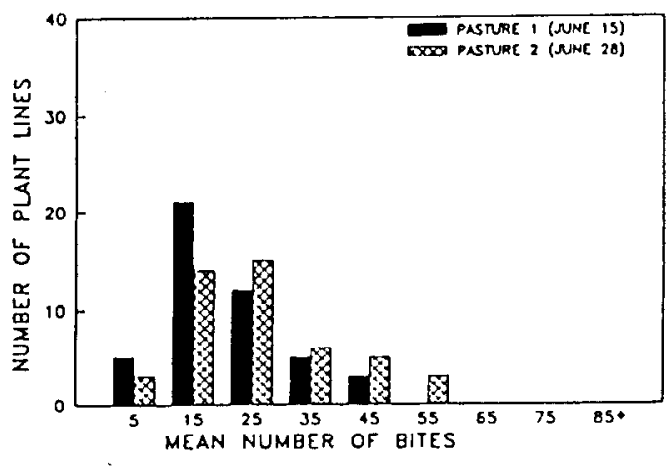

TRIAL 4

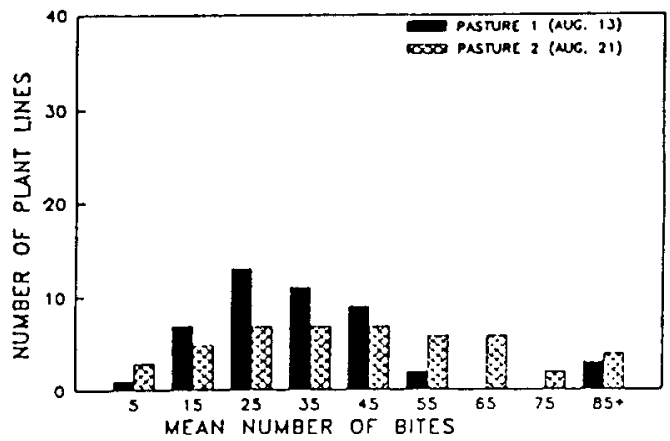

Fig. 1. Mean number of bites taken from 46 clonal RS hybrid lines for 2 pastures over 4 trials in 1981 . 
sprinkler irrigated and the plot was cleared of any feces, herbage litter, and debris.

\section{Analysis Procedures}

In 1981, the total number of bites/plant line/trial was used to establish relative preferences by individual steers. Repeated measures were used for the analysis of variance to determine significance of differences in bites/plant line due to the plant line, trial, and plant line by trial interaction. Trials were analyzed by pasture due to the 2-week intervals between pasture collection periods.

In 1982, differences in utilization trials were determined by analysis of variance. Pastures 1 and 2 were considered the major replication in these analyses. The variation among replications was considerably less than the variation among trials; therefore, variation between trials was used as the error term to test significance. Comparisons in the rankings of the RS lines preferred by cattle between years were analyzed using nonparametric, rank correlations (Spearman's Rho, Siegel 1956). The plant rankings between years were also analyzed with plant line and year considered as main effects.

\section{Results and Discussion}

\section{Grazing Trials}

Distributions of mean number of bites taken by the steers for each of the 46 RS hybrid lines for all 4 trials for the 2 pastures were quite similar across trials (Fig. 1). Bite distribution in both pastures was skewed left in trials 1,2, and 3; close to normal distribution for pasture 1 during trial 4 and somewhat platykurtic for pasture 2 , trial 4.

In trial 2, there was a notable absence of any lines being grazed at the extreme upper end of the bite scale in comparison to the other 3 trials. Clone 30 ranked either number 1 or 2 in terms of most total bites in every trial but trial 2 . Clone 30 also had the most bites when averaged over the 4 trials (Fig. 2). Lines 9, 15, 23, 32, and 44 were also highly preferred over other clonal lines. A separation of pasture influence in the summary (Fig. 2) showed a high degree of

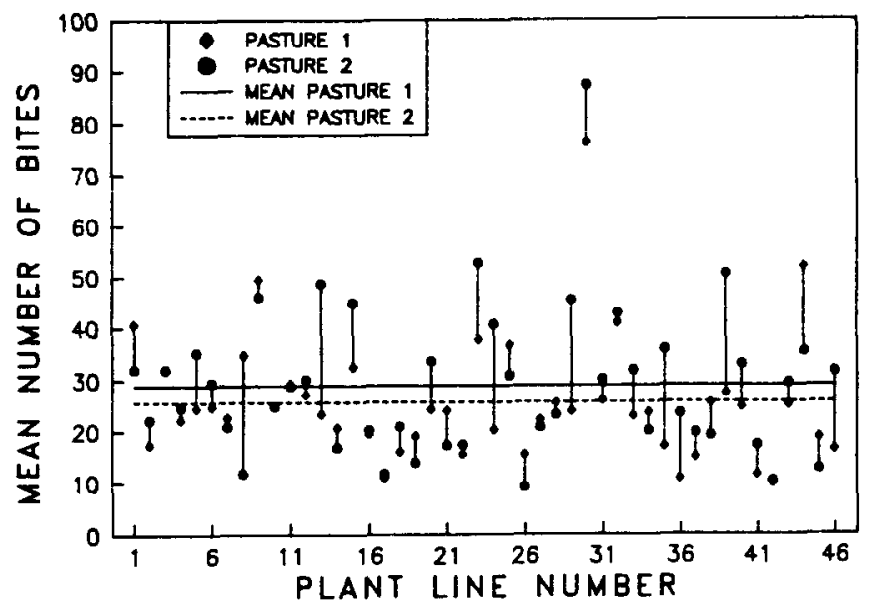

Fis. 2. Mean bite count distributions for the 46 clonal RS hybrid lines for 4 trials in 2 pastures from 1981 grazing trials.

similarity between pastures with regard to mean number of bites for respective plant lines over the 4 trials. Notable differences were observed for plant lines $8,13,24,29,35$, and 39 . These differences may be attributed to changes in phenology during the first trial due to the 2-week interval when pastures were first grazed and the subsequent effects this difference had on latter trials. These phenological changes contributed to the major differences in plants between pastures, but clone 30 was the most preferred line in both pastures. Variation inherent in the animal grazing process was also undoubtedly a factor contributing to differences over trials.

In a comparison of the average number of bites per plant vs. trial, the trend in average number of bites increased steadily from trial 1 to trial 4 and was in general, greater for pasture 2 then pasture 1. Although slight, this trend may be explained by the
TRIAL 1 ( MAY 27)

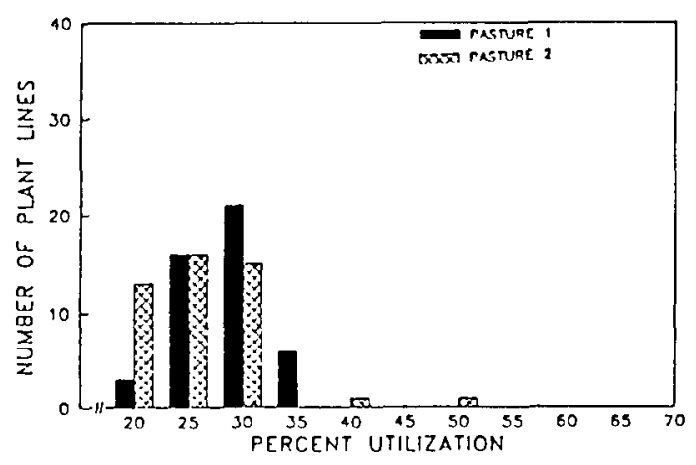

TRIAL 3 (JULY 21)

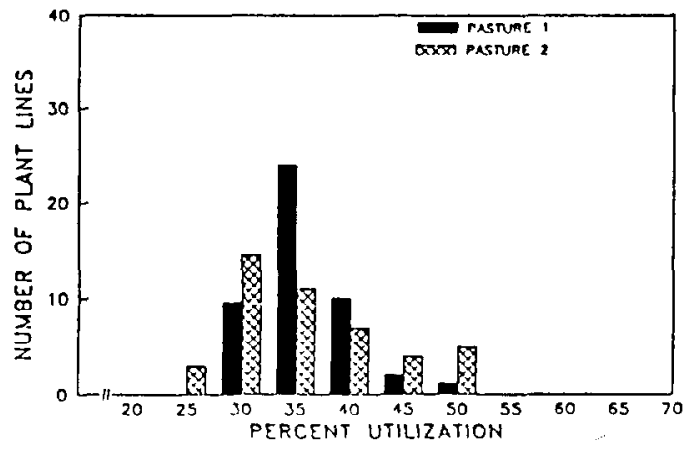

TRIAL 2 (JUNE 23)

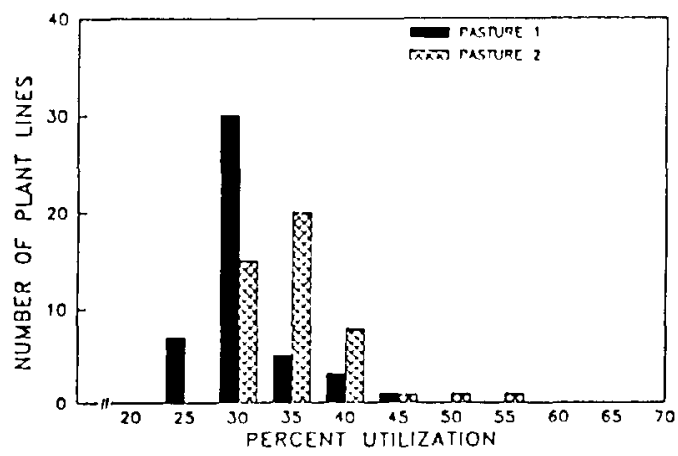

TRIAL 4 (AUG. 18)

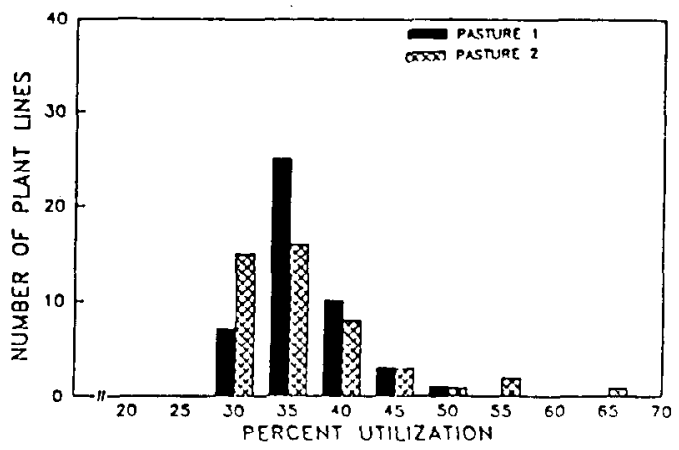

Fig. 3. Percent utilization of plant lines over 4 trials. 
adaptation of the steers to the trial procedures as the summer progressed. It may also be related to plant morphology. Average height of plants in trial 1, pasture 2 was $87 \mathrm{~cm}$ compared to $66 \mathrm{~cm}$ for pasture 1 . Thus, availability of preferred clones may have been a factor limiting the number of bite.

In trial 2, pastures 1 and 2 , and trial 3, pasture 1 , the range in total bites per plant differed from other trials (Table 1). Each trial had a difference between the most-preferred and the leastpreferred plants of less than 300 bites. This corresponds to a time

Table 1. Bite count means and ranges for each trial and pasture, 1981.

\begin{tabular}{ccccc}
\hline \hline & & & \multicolumn{2}{c}{ Bite Count } \\
\cline { 4 - 5 } Trial & Pasture & Date & Mean & \multicolumn{1}{c}{ Range } \\
\hline 1 & 1 & 15 May & 407 & $3-410$ \\
1 & 2 & 30 May & 585 & $4-589$ \\
2 & 1 & 15 June & 283 & $33-316$ \\
2 & 2 & 30 June & 245 & $32-277$ \\
3 & 1 & 15 July & 258 & $69-327$ \\
3 & 2 & 30 July & 417 & $35-452$ \\
4 & 1 & 14 Aug. & 556 & $38-594$ \\
4 & 2 & 28 Aug. & 491 & $20-611$ \\
\hline
\end{tabular}

span from 15 June to 15 July when the actual variation in number of bites per plant was greatly reduced. Regrowth of the plants during this time period was substantial and quite uniform over the plot, and the outward morphological variations (i.e., plant size, phenology, leaf scores) between plants were minimized. This was a dominant factor in reducing variation in the number of bites taken between plants.

Significant differences $(P<0.01)$ in plant preference were also found among clonal lines and between trials, suggesting that steers were detecting a real difference among clonal lines. For example, line 30 had a maximum of $87 \pm 1$ bites per plant on the average as opposed to lines 26 and 42 with fewer than $9 \pm 1$ bites per plant. Differences between trials indicated the seasonality of preferences and the effect that changes in plant maturity have on preference. These findings support those of other studies with other species on the effects of season and maturity on preferences exhibited by domestic livestock (Ivins 1952, Garner 1963).

Differences in preference for regrowth forage was less pronounced in the eraly summer as demonstrated by the trial 2 results. This supports earlier observations of a decreased range in bites in trials 2 and decreased variation between plant lines with regard to many morpholocial characteristics. Thus, management of a plant such as the RS hybrid greatly affects the manner and degree in which cattle express a preferred use.

\section{Grazing Trials}

Final utilization estimates of the cloned plants grazed in each trial were used to rank plant lines in the 1982 group preference studies (Fig. 3). These distributions were slightly skewed left. Distributions in 1982 showed small changes from trial to trial as compared with those in 1981 . However, there was strong evidence that a few plants were highly preferred (Fig. 4). Plant line 30 ranked high in preference in both years, but lines 14 and 43 were high only in 1982 . Pasture effects were not pronounced, although heaviest use of the plants was consistently recorded on pasture 2 , while the utilization values for pasture 1 were grouped into 4 or 5 utilization categories. First and final average utilization estimates for each plant over the 4 trials are summarized in Figure 4 and shows similarity between the 2 time periods indicating that a 30-min time period was sufficient to separate preference differences between plants. The major change from time period 1 to final time was essentially one of magnitude. Average utilization over all plants increased steadily from trial $1(29 \pm 3 \%)$ to trial $3(39 \pm 3 \%)$ then leveled off. Significant differences were found among trials, plant

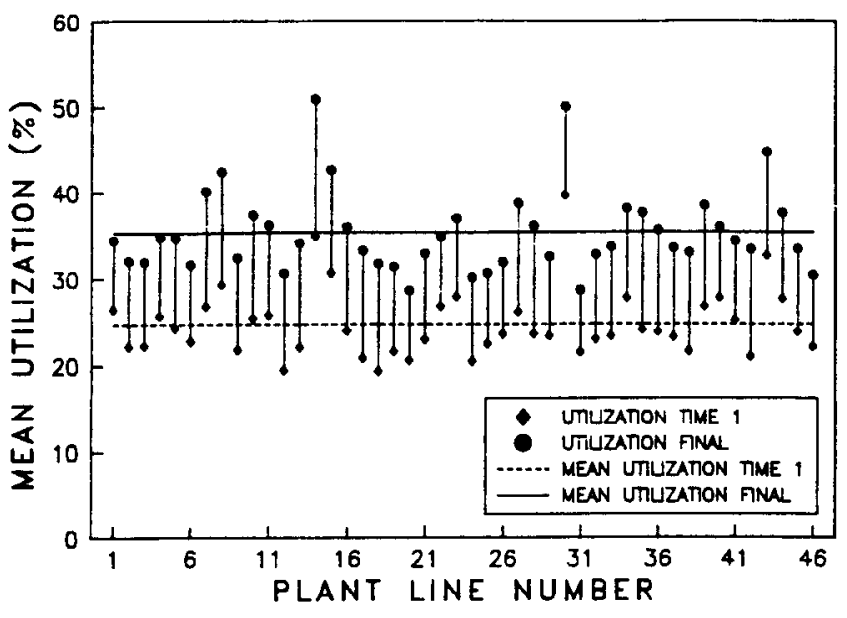

Fis. 4. Mean percent utilizations of 46 clonal $R$ S hybrid lines for 2 pastures over 4 trials in 1982.

line and replication $(P<0.01)$. The plant line by trial interaction was not significant $(P>0.05)$. Thus, plants preferred or discriminated against were consistent from trial to trial although there were differences between trials in the amount of plant use.

\section{Between-Year Comparisons}

Rank correlations were calculated between bite count data (1981) and utilization data (1982) to evaluate the consistency of plant rakings between yaars. For trial 1 on both pastures, relationship of bites and the final time period utilization estimates were significant $(P<0.01)$ with $R^{2}$ value of 0.56 and 0.51 , respectively.

Results from trials in both years suggest a similar conclusion regarding plant preference. Plant lines highly preferred in 1981 and 1982 were similar and the preferred clones were found to be in lines originating from a common parental selection. The heritability of factor(s) in the RS hybrid that affect preference by cattle appears to be quite high; similar results were reported by Barnes et al. (1970) for reed canarygrass where an alkaloid appeared to be the causative agent. There was more variability in preferences between trials at the lower end of the rank scale than in the top-ranked group. In general, plant numbers 1 to 30 were selections based on preferences from previous animal grazing trials and 31 to 46 were selections based on agronomic traits. Plants selected on the basis of both criteria were represented in both preferred and nonpreferred plant categories.

Analysis of the rankings of lines in trials 3 and 4 from both pastures and both years showed the effect of plant line to be significant $(P<0.01)$. Analyses based on bites and utilization also indicated a similar result. The line $X$ year interaction was also significant indicating that the relative rankings of lines were not always consistent over years. For example, line 14 clones were relatively unused in 1981 , but were preferred and heavily used in 1982. This suggests that relative plant preferences can change, and some variations will occur from year to year. However, differences in line 14's ranking could also be attributed to the differences between bite count and utilization measurements and what they effectively measure. Bite counts tend to be a more absolute type of measurement than utilization estimates in that they do not consider the proportion of the plant removed or other plant traits. Utilization estimates are a more relative type of measure and account for overall plant size and structure differences.

\section{Conclusions}

Significant differences in preferences by steers $(P<0.01)$ among the $\mathbf{4 6}$ clonal lines of the RS hybrid were shown for 2 successive years. Preference rankings determined by bite counts for lines 
selected the first year were not identical to those selected a second year by percent utilization although lines with high preference rankings the first year were generally preferred the second year. Preference was consistent over the grazing season with the exception of a 4-week period in early summer when phenological differences between plant lines were minimal. During the period from mid June to mid July, the range in bite counts per plant decreased and selective differences by cattle for the different hybrid lines were not as pronounced. This phenomenon was attributed mainly to abundant regrowth present on all plant lines for this period of the growing season. Overall some very specific preferences for clones were shown among the 46 lines. For example, plant line 30 was one of the most preferred plants in 7 out of 8 trials in 1981. It was also highly preferred in 1982 trials and ranked in the top 3 of the preferred plants in all trials in both pastures.

Results obtained from grazing trials where steers grazed individually or as a group were also similar. This suggests either method to measure preferences is acceptable and results are generally comparable. However, there were some inconsistencies. Line 14 , for example, was not among the top 10 plants in any trial in 1981 , but was no lower than 5 th in any trial during 1982 . Differences in the measurement of cattle preference during the 2 years may have been attributable to differences in bite count and utilization estimates. Also, relatively small differences between the hybrids with regard to many of the characteristics measured any account for the results. Had a population been selected at random rather than on the basis of high palatability and agronomic traits, perhaps rankings would have been more consistent.

\section{Literature Cited}

Asay, K.H., I.T. Carlson, and C.P. Wilsie. 1968. Genetic variability in forage yield, crude protein percentage and palatability in reed canarygrass, Phalaris arundinacea [L.]. Crop Sci. 60:568-571.

Asay, K.H., and D.R. Dewey. 1981. Registration of Agropyron repens $X$ A. spicatum germplasms RS-1 and RS-2. Crop Sci. 21:351.

Barnes, R.F., W.E. Nyquist, and R.C. Pickett. 1970. Variation in acceptability and covariation with agronomic characteristics in Phalaris arundinacea [L.]. Proc. 11 th Int. Grassl. Congr. p. 202-206.

Currie, P.O., R.S. White, and K.H. Asay. 1981. Cattle preference and plant selection within a hybrid grass. Proc. XIV Int. Grassl. Congr. p. 675-678.

Dewey, D.R. 1983. Historical and current taxonomic perspectives of Agropyron, Elymus and related genera. Crop Sci. 23:637-642.

Dewey, D.R. 1984. The genomic system of classification as a guide to intergeneric hybridization with the perennial Triticeae. p. 204-279. In: J.P. Gustafson (ed.). Gene manipulation in plant improvement. Plenum Publ. Corp., New York.

Garner, F.J. 1963. The palatability of herbage plants. J. Brit. Grassl. Soc. 18:78-89.

Ivins, J.D. 1952. The relative palatability of herbage plants. J. Brit. Grassl. Soc. 7:43-47

Pechanec, J.F., and G.D. Pickford. 1937. A comparison of some methods used in determining percentage utilization of range grasses. J. Agr. Res. 54:753-765.

Peterson, R.G., P.H. Weswig, and J.R. Cowan. 1958. Measuring palatability differences in tall fescue by grazing sheep. Agron. J. 50:117-119.

Siegel, S.S. 1956. Nonparametric statistics for the behavioral sciences McGraw-Hill Book, Co., Inc. New York.

Steel, R.G.D., and J.H. Torrie. 1980. Principles and procedures of statistics. McGraw-Hill Book Co., Inc., New York.

\title{
Range Research: Basic Problems and Techniques
}

\author{
editors: C. Wayne Cook and James Stubbendieck
}

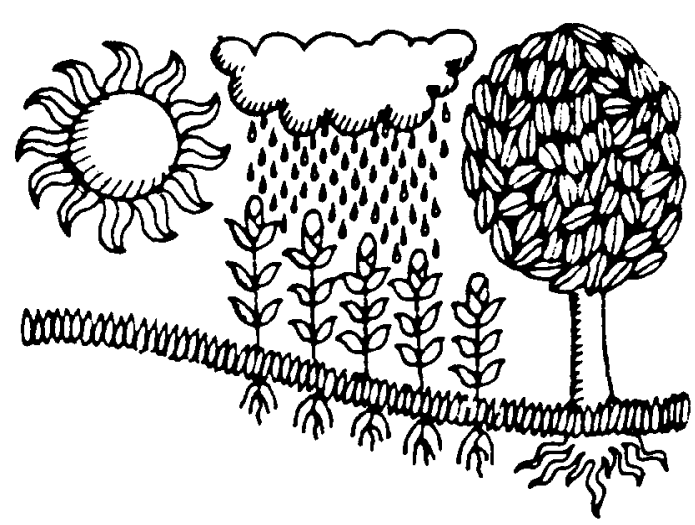

RANGE RESEARCH: BASIC PROBLEMS AND TECHNIQUES, a major revision of an earlier publication of the National Academy of Science, presents steps in research planning, evaluation of results, and methods and procedures in range research, including sampling techniques and experimental design. Chapter titles include: The Range Research Problem, Assessment of Habitat Factors, Methods of Studying Vegetation, Studies of Root Habits and Development, Methods of Measuring Herbage and Browse Utilization, Livestock Selection and Management in Range Research, Methods for Studying Rangeland Hydrology, Economic Research in Range Management, Sampling Methods with Special Reference to Range Management, Experimental Design, and Problems Involved in the Application of Research Techniques in Range Management. The book is designed to serve as a reference guide for range research methodology and as a textbook for advanced students who anticipate careers in this increasingly important field.

1986. 336 pages ISBN 09603692-3-6. \$28/hard.

Society for Range Management

1839 YORK STREET • DENVER. COLORADO 80206 • USA 